\title{
Efficacy and safety of hydroxychloroquine as add-on therapy in uncontrolled type 2 diabetes patients who were using two oral antidiabetic drugs
}

\author{
H. N. Chakravarti ${ }^{1} \cdot$ A. Nag ${ }^{1}$ \\ Received: 28 April 2020 / Accepted: 5 June 2020 / Published online: 27 June 2020 \\ (c) The Author(s) 2020
}

\begin{abstract}
Objective To evaluate the Safety and Efficacy of Hydroxychloroquine as add-on therapy in uncontrolled type 2 diabetes patients who were using two oral antidiabetic drugs.

Materials and methods This was a double blind, placebo controlled, parallel group study in 304 inadequately controlled type 2 diabetes (T2DM) subjects with two oral antidiabetic drugs (glimepiride $4 \mathrm{mg}$ and metformin $500 \mathrm{mg}$ ) were randomised to hydroxychloroquine (HCQ) $200 \mathrm{mg}, 300 \mathrm{mg}, 400 \mathrm{mg}$ once daily (OD) or placebo. Dose of hydroxychloroquine was selected as per body weight of the subject. Primary end point was glycated haemoglobin (HbA1c) change at week 12 from baseline. Secondary endpoint was change in fasting plasma glucose (FPG), post prandial plasma glucose (PPG), body weight and any adverse reaction including no of hypoglycemic events, as well as a change in the percentage of subjects with A1C $<7.0 \%$ and $>6.5 \%$ after 12 weeks of treatment.. In follow-up of $400 \mathrm{mg}$ once daily was once again divided to $200 \mathrm{mg}$ twice daily (BD) to study the effect on tolerability profile for further 12 weeks.

Results Hydroxychloroquine was associated with significant reduction in HbA1c from baseline (7-8.5\%) in 12 weeks $-0.78 \%,-0.91 \%$ and $1.2 \%$ for hydroxychloroquine $200 \mathrm{mg}, 300 \mathrm{mg}$ and $400 \mathrm{mg}$ OD, respectively, versus $0.13 \%$ with placebo $(P<0.005)$. FPG and PPG were reduced by -25 to $-38 \mathrm{mg} / \mathrm{dl}$ and $34-53 \mathrm{mg} / \mathrm{dl}$, respectively. Body weight also reduced in each group of HCQ. Hypoglycemia was reported only with $300 \mathrm{mg}(1.2 \%)$ and $400 \mathrm{mg}$ (2.1\%) group of HCQ. It was observed that patients who complains with mild GI disturbance with HCQ $400 \mathrm{mg}$ glycemic efficacy was maintained with $200 \mathrm{mg}$ BD with significant relief of the symptoms.

Conclusion Hydroxychloroquine added to sulphonylurea and metformin, improves glycemic control significantly in T2DM patients. Glycemic effect of different dose of hydroxychloroquine is dose dependent. The safety/tolerability profile of hydroxychloroquine was favourable except GI disturbance which is more frequent with $400 \mathrm{mg}$. This can be avoided with $200 \mathrm{mg}$ $\mathrm{BD}$ without compromise on efficacy.
\end{abstract}

Keywords Hydroxychloroquine $\cdot$ Type 2 diabetes $\cdot$ HbA1c $\cdot$ FPG $\cdot$ PPG

\begin{tabular}{|c|c|}
\hline \multicolumn{2}{|c|}{ Abbreviations } \\
\hline T2DM & Type 2 diabetes mellitus management \\
\hline HbA1c & Glycated haemoglobin \\
\hline FPG & Fasting plasma glucose \\
\hline PPG & Post prandial plasma glucose \\
\hline HCQ & Hydroxychloroquine \\
\hline
\end{tabular}

A. Nag

dravicknag@ rediffmail.com

1 Department of Medicine, Medical College and Hospital, Kolkata, West Bengal, India

\section{Introduction}

The International Diabetes Federation (IDF) reported that, at present, there are 415 million people worldwide suffering from DM, aged between 20 and 79 years old, the global prevalence being of $8.8 \%$, and it is estimated that in 2040 their number will grow up to 642 million, with a prevalence of $10.4 \%$ [1]. In India as per 2015 scenario, 69.1 million cases of diabetes were reported [2].

Metformin is known for the first-line therapy for type 2 diabetes mellitus (non-insulin dependent diabetes mellitus). It is the common drug prescribed worldwide. Metformin is a biguanide agent, and it lowers both basal and post-prandial plasma glucose (PPG) [3]. American Diabetes Association 
(ADA) recommends metformin to treat individuals diagnosed with type 2 diabetes and recommends that glycated haemoglobin $(\mathrm{HbA} 1 \mathrm{c})$ should be maintained below or around 7\% [4].

The latest position statement from the ADA recommends initiating a combination of two non-insulin agents when the patients have a high baseline HbAlc $(\geq 9.0 \%)$ because these patients are unlikely to achieve target A1c with metformin monotherapy [5]. It has been hypothesized that combining metformin and an agent from another class with a different mechanism of action may help to preserve $\beta$-cell function and thereby maintain a long-term glycaemic efficacy or 'durability' [6]. The major classes of oral antidiabetic medications include biguanides, sulfonylureas, meglitinide, thiazolidinedione (TZD), dipeptidyl peptidase 4 (DPP-4) inhibitors, sodium-glucose cotransporter (SGLT-2) inhibitors, and $\alpha$-glucosidase inhibitors. If the $\mathrm{HbA} 1 \mathrm{C}$ level rises to $7.5 \%$ while on medication or if the initial $\mathrm{HbA} 1 \mathrm{C}$ is $\geq 9 \%$, combination therapy with two oral agents, or with insulin, may be considered [7].Even before initiating insulin therapy, GLP-1 receptor agonists are recommended as add-on therapy for patients who do not achieve their A1C target after 3 months of metformin therapy [8].

However, most patients initially respond to sulfonylureas and/or metformin at the starting stage, later on these agents lose their effectiveness with time; comparable long-term data is not yet available for the alpha glucosidase inhibitors, the meglitinides and the thiazolidinediones [9]. Insulin therapy is not only costly but is not preferred due to poor patients' compliance in parenteral application. New generation thiazolidinediones class of antidiabetic drugs, though useful in glycemic control, is associated with several adverse effects such as excessive risk of congestive heart failure, acute myocardial infarction, increased rate of bone loss and liver toxicity [9]. In the light of failure of monotherapy of antidiabetic drugs in glycemic control and increased adverse effects when administered at high doses of antidiabetic drugs for getting better glycemic control, newer medications for diabetes are needed, which will have good anti-hyperglycemic effect, as well as good tolerability profile. Though there is already an option of GLP-1 RA and SGLT-2 inhibitors and apart of the efficacy of glycemic control they also offer proven cardiovascular and renal benefits, but due to their exorbitant cost they are beyond the reach of many patients especially in developing country like India. Therefore the need of adding second oral antihyperglycemic agent is required when metformin or sulfonylureas do not achieved a HbA1C target or metformin monotherapy at maximal tolerated dose over 3-6 months.

In 2014 hydroxychloroquine was approved by Drug Controller General of India (DCGI) for the management of Type 2 Diabetes (T2DM) as an adjacent to diet and exercise to improve glycemic control in patients with T2DM on combination of sulfonylurea and metformin and even endorsed by RSSDI (Research Society for the Study of Diabetes in India) clinical practice recommendations for the management of type 2 diabetes mellitus 2017 [10]. Hydroxychloroquine (HCQ) improve glucose tolerance and insulin sensitivity by inhibition of insulin degradation. It slows breakdown of the internalized insulin-receptor complex and has a modest effect on reducing glycemic parameters along with reduction of pro-inflammatory markers [11]. An Indian randomized controlled phase 3 trials showed that HCQ $(400 \mathrm{mg})$ as compared to pioglitazone $(15 \mathrm{mg})$ lowers HbA1c, LDL cholesterol levels and lead to weight loss in patients with type 2 diabetes [12].

Objective of the current study was to evaluate the Safety and Efficacy of Hydroxychloroquine as add-on therapy in uncontrolled type 2 diabetes patients who were using two oral antidiabetic drugs. A different dose was used to determine the dose dependent efficacy and safety which has compared with placebo.

\section{Material and methods}

This was a randomized, double blind, placebo controlled, parallel group, single centre, prospective study. Subjects were randomised to three groups of hydroxychloroquine depending on dose of $200 \mathrm{mg}, 300 \mathrm{mg}$ and $400 \mathrm{mg}$, along with placebo group. In follow-up of $400 \mathrm{mg}$ once daily was once again divided to $200 \mathrm{mg}$ twice daily (BD) to study the effect on tolerability profile for further 12 weeks.

The study was initiated only after obtaining necessary approvals from Institutional ethics committee of Medical College, Kolkata (Ref No. MC/kol/IEC/Nonspon/641/11-2017). Patient information sheet (PIS) was discussed with each enrolled patients or legally acceptable representative (LAR)/impartial witness (in case of illiterate patients) as applicable. The complete informed consent process was in adherence with the current regulatory requirement (s). The study was conducted in accordance with the principles in the Declaration of Helsinki and was consistent with good clinical practices and applicable regulatory requirements.

At screening visit, demographic characteristics, medical history, and details of previous and current medication (s) including details of metformin and sulfonylurea dose and duration was recorded. Complete physical examination was performed; vital signs, body weight, was recorded. Pathological test was performed for HbA1c, FPG, 2-h PPG (postprandial glycemia After a standardized meal) at different interval and requirements of the study from Kolkata Medical College pathology department or NABL (National Accreditation Board for Testing and Calibration Laboratories) accredited pathological laboratory as per the convenience 
and economical affordability of subjects. Electrocardiogram (ECG) was recorded at this visit. Detailed ophthalmological examination (visual acuity test, fundoscopic test, visual field test, expert slit lamp test and amsler grid test) was performed to identify any grade of diabetic retinopathy and maculopathy. All female patients of child bearing potential was undergo a urine pregnancy test (UPT). A negative urine pregnancy test was obtained before including any patient on the study. Compliance to study medications was assessed based on returned used study drugs and patients diary.

\section{Dose selection criteria}

The most recent 2011 guidelines from the American Academy of Ophthalmology (AAO) recommend the dose of $\mathrm{HCQ} \leq 6.5 \mathrm{mg} / \mathrm{kg}$ based on ideal body weight to minimize toxicity [13]. Even 2016 guideline recommend $\mathrm{HCQ} \leq 5 \mathrm{mg} /$ $\mathrm{kg}$ of base ingredient on real body weight [14]. Based on this for initiating treatment patients who had body weight $\geq 60 \mathrm{~kg}$ was selected for HCQ $400 \mathrm{mg}$ and $300 \mathrm{mg}$, patients $<60 \mathrm{~kg}$ body weight was selected suitable for $300 \mathrm{mg}$ and $200 \mathrm{mg}$ only.

\section{Study population}

Eligible patients were aged 18-75 years with T2DM, who were inadequately controlled (HbA1c $\geq 7-8.5 \%$ ) on stable combination therapy with glimepiride $4 \mathrm{mg}$ and metformin $500 \mathrm{mg}$. This two therapy dosage was chosen as this are two most frequently prescribed and tolerated dose specially in India. Patients were excluded if any history or presence of any retinopathy of any grade including diabetic retinopathy requiring laser therapy, evidence of an imminent need for retinal laser therapy, uncorrected visual acuity $<20 / 100$, abnormal visual fields, difficulty to examine optic disc, or evidence of retinal pigment epithelial abnormalities and patients with history or risk of macular oedema. Patients with recent ( $<1$ year) $\mathrm{CV}$ events i.e., myocardial infarction/ACS, stroke or has undergone coronary artery bypass surgery, percutaneous transluminal coronary angioplasty or transient ischemic attack, or history of congestive heart failure, or unstable angina, abnormal renal function (serum creatinine $\geq 1.5 \mathrm{mg} / \mathrm{dl}$ ), history of symptomatic autonomic neuropathy or chronic gastroparesis, active gastrointestinal disorders (gastric and duodenal ulcer) were excluded from the study.

\section{Study end points}

Primary end point was glycated haemoglobin (HbA1c) change at week 12 from baseline. Secondary endpoint was change in fasting plasma glucose (FPG), post prandial plasma glucose (PPG), body weight and any adverse reaction including no of hypoglycemic events, as well as a change in the percentage of subjects with $\mathrm{A} 1 \mathrm{C}<7.0 \%$ and $>6.5 \%$ after 12 weeks of treatment.

\section{Safety assessments}

Safety assessments included the number of patients with adverse events (AEs), including AEs of special interest pre specified for inferential testing without multiplicity control (symptomatic hypoglycaemia (defined as episodes with clinical symptoms reported by the investigator as hypoglycaemia; biochemical documentation not required), and AEs associated with gastro intestinal disturbance. Investigator have confirmed hypoglycaemia whenever reported by patients (initially detected by SMBG) from a NABL accredited pathological laboratory as per the convenience and economical affordability of subjects.

\section{Statistical methods}

Descriptive statistics was used to compare the demographic and baseline disease characteristics. Data was presented in terms of mean $\pm \mathrm{SD}$, median, percentiles or range for continuous variables and percentage for categorical variables. All the patients was compared at baseline for homogeneity using ANOVA test for continuous variables and Chi square test or Fisher's exact test for categorical variable. For all statistical tests the significance level was set as 0.05 . SAS 9.3 was used for statistical analysis.

\section{Sample size calculation}

Sample size of 61 patients in each group was required to give more than $80 \%$ power with $\alpha=0.017$ (adjusted for three potential comparisons) to detect a treatment difference of $0.4 \%$ in $\mathrm{HbA} 1 \mathrm{c}$ for Hydroxychloroquine $200 \mathrm{mg}$, Hydroxychloroquine $300 \mathrm{mg}$ and Hydroxychloroquine $400 \mathrm{mg}$ with placebo and assumed a standard deviation of $1 \%$.

\section{Randomization procedure}

Randomization codes was generated using block randomization programme in SAS $9.3^{\circledR}$. Patient's identification number were used in patient's diary. All patients were received stable dose of metformin $500 \mathrm{mg}$ and glimepiride $4 \mathrm{mg}$ along with one of the therapies, either placebo, or active hydroxychloroquine $200 \mathrm{mg}$, or $300 \mathrm{mg}$ or $400 \mathrm{mg}$ tablets. The study drugs including placebo and active drug was arranged by the investigators at their own cost from local generic manufacturing agency. 


\section{Results}

Of 395 patients screened for the treatment cohort, 326 were randomly assigned (Fig. 1). Demographic and baseline characteristics are reported in (Table 1). Baseline demographics were generally similar between groups. Patient's disposition was details in (Fig. 1).

Mean age of patients and gender distribution were almost similar in all groups. All group subjects had comparable FPG, PPG and HbA1c at the baseline. As per body weight hydroxychloroquine dose were selected. Patient's $\geq 60 \mathrm{~kg}$ were selected for hydroxychloroquine $400 \mathrm{mg}$ dose.

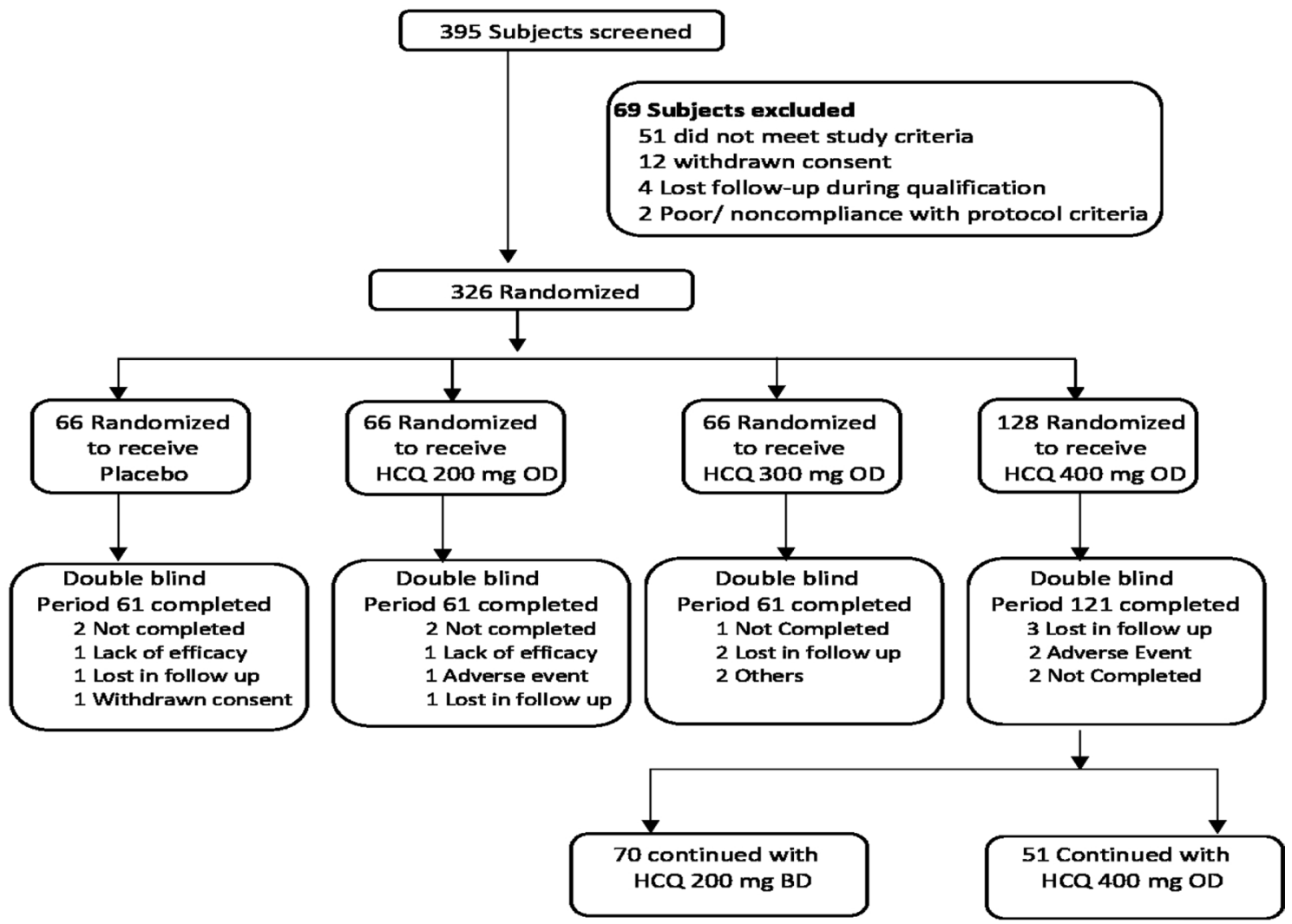

Fig. 1 Patient disposition

Table 1 Demographic and baseline characteristics of randomly assigned patients in the treatment cohort

\begin{tabular}{llllll}
\hline Characteristics & $\begin{array}{l}\text { Met + SU + pla- } \\
\text { cebo }(N=61)\end{array}$ & $\begin{array}{l}\text { Met }+ \text { SU+HCQ } \\
200 \mathrm{mg}(N=61)\end{array}$ & $\begin{array}{l}\text { Met + SU+HCQ } \\
300 \mathrm{mg}(N=61)\end{array}$ & $\begin{array}{l}\text { Met+SU+HCQ } \\
400 \mathrm{mg}(N=121)\end{array}$ & $P$ value \\
\hline Age (years) & $53.36 \pm 7.8$ & $53.36 \pm 8.5$ & $51.76 \pm 8.0$ & $52.96 \pm 9.6$ & 0.953 \\
Sex (male/female) & $32 / 29$ & $39 / 22$ & $41 / 20$ & $81 / 40$ & 0.305 \\
Weight (kg) & $62.6 \pm 6.1$ & $59.6 \pm 6.7$ & $61.6 \pm 5.4$ & $70.6 \pm 8.2$ & 0.191 \\
BMI (kg/m $\left.{ }^{2}\right)$ & $25.1 \pm 2.5$ & $24.3 \pm 2.1$ & $24.8 \pm 2.3$ & $25.5 \pm 2.6$ & 0.219 \\
Duration of type 2 & $6.46 \pm 5.0$ & $5.66 \pm 5.0$ & $6.16 \pm 4.7$ & $6.46 \pm 5.7$ & 0.329 \\
diabetes (years) & & & & & \\
HbA1C (\%) & $7.72 \pm 0.5$ & $7.83 \pm 0.5$ & $7.89 \pm 0.5$ & $7.93 \pm 0.5$ & 0.047 \\
FPG (mg/dl) & $157 \pm 32$ & $164 \pm 38$ & $168 \pm 42$ & $170 \pm 45$ & 0.030 \\
PPG (mg/dl) & $269 \pm 58$ & $275 \pm 53$ & $278 \pm 56$ & $282 \pm 51$ & 0.052 \\
Hypertension & $36(59 \%)$ & $48(78 \%)$ & $47(77 \%)$ & $96(79 \%)$ & 0.917 \\
Dyslipidemia & $38(62 \%)$ & $46(75 \%)$ & $44(72 \%)$ & $91(75 \%)$ & 0.879
\end{tabular}

Data are means $\pm \mathrm{SD}, n(\%)$, or median (interquartile range). Analysed by one-way ANOVA $B M I$ body mass index, $H b A 1 c$ glycated haemoglobin, $F P G$ fasting plasma glucose, $P P G$ post-prandial glucose 
Intergroup $\mathrm{p}$ value for demographic and baseline characteristic were statistically non-significant (Table 1).

Hydroxychloroquine was associated with significant reduction in $\mathrm{HbA} 1 \mathrm{c}$ from baseline $(7-8.5 \%)$ in 12 weeks $-0.78 \%,-0.91 \%$ and $1.2 \%$ for hydroxychloroquine $200 \mathrm{mg}$, $300 \mathrm{mg}$ and $400 \mathrm{mg}$ OD, respectively, versus $0.13 \%$ with placebo $(P<0.005)$. HbA1c reduction was highest with HCQ $400 \mathrm{mg}$ as compare to other group. It has observed a dose dependent reduction across HCQ group and was statically significant as compared to placebo group (Table 2) (Fig. 2).

After further 12 weeks continuation glycemic parameters was almost similar in both HCQ $400 \mathrm{mg}$ OD group and HCQ $200 \mathrm{mg}$ BD group and $P$ value of in-between group was nonsignificant (Table 3 ).

Significantly greater mean reductions in FPG and PPG were observed with all doses of hydroxychloroquine $(-25 \mathrm{mg} / \mathrm{dl}$ to $-38 \mathrm{mg} / \mathrm{dl}$ and $-34 \mathrm{mg} / \mathrm{dl}$ to $-53 \mathrm{mg} / \mathrm{dl}$, respectively) compared with placebo $(+2 \mathrm{mg} / \mathrm{dl}$ and $-12 \mathrm{mg} / \mathrm{dl}$ respectively) (Fig. 3). FPG and PPG reduction were gradually increase with the increasing dose of hydroxychloroquine and the intergroup $\mathrm{p}$ value was statistically significant. Even after 12 week further follow-up of FPG and PPG were almost similar in both HCQ $400 \mathrm{mg}$ OD group and HCQ $200 \mathrm{mg} \mathrm{BD}$ group and $\mathrm{p}$ value of in-between group was also non-significant (Table 3).

Efficacy was further assessed by determining the proportion of subjects who achieved an A1C $<7.0 \%$ at week 12 of the study (Table 4).

Body weight reductions were seen in all hydroxychloroquine groups relative to placebo (Fig. 4). Hydroxychloroquine reduced body weight from baseline; these reductions were -0.7 to $-2.1 \mathrm{~kg}$ at week 12 . Were as in placebo group $0.4 \mathrm{~kg}$ weight was increased from baseline. Weight loss appeared to be greatest in subjects in the hydroxychloroquine $400 \mathrm{mg}$ groups. Even when hydroxychloroquine dose was further followed up for 12 weeks more there was not much significant difference was noticed in between hydroxychloroquine $200 \mathrm{mg}$ BD group and hydroxychloroquine $400 \mathrm{mg}$ OD group. All patients were on strict diet regimen which was monitored with periodic interval and was strictly advised for adequate exercise regime.

Incidence of AE was almost in similar pattern across the hydroxychloroquine group, except there was a higher gastrointestinal AE with higher dose of hydroxychloroquine (Table 5). Mild to moderate AE was determined by the investigators depending upon the severity and intensity of the event. Symptomatic hypoglycemia was considered as one of the most serious AE but no symptomatic hypoglycemia was requires additional medical assistance. It has been observed that there was no discontinuation of the drug because of any AE. Hydroxychloroquine was well tolerated in this study, with no evident increase in overall $\mathrm{AE}$

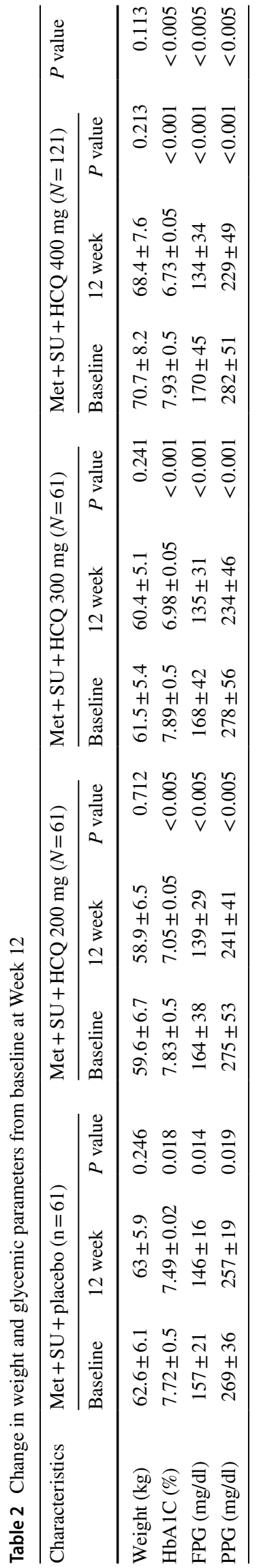


Fig. 2 Change in $\mathrm{HbA} 1 \mathrm{c}$ from baseline to week 12 in subjects with type 2 diabetes on metformin and sulfonylurea after addition of hydroxychloroquine or placebo

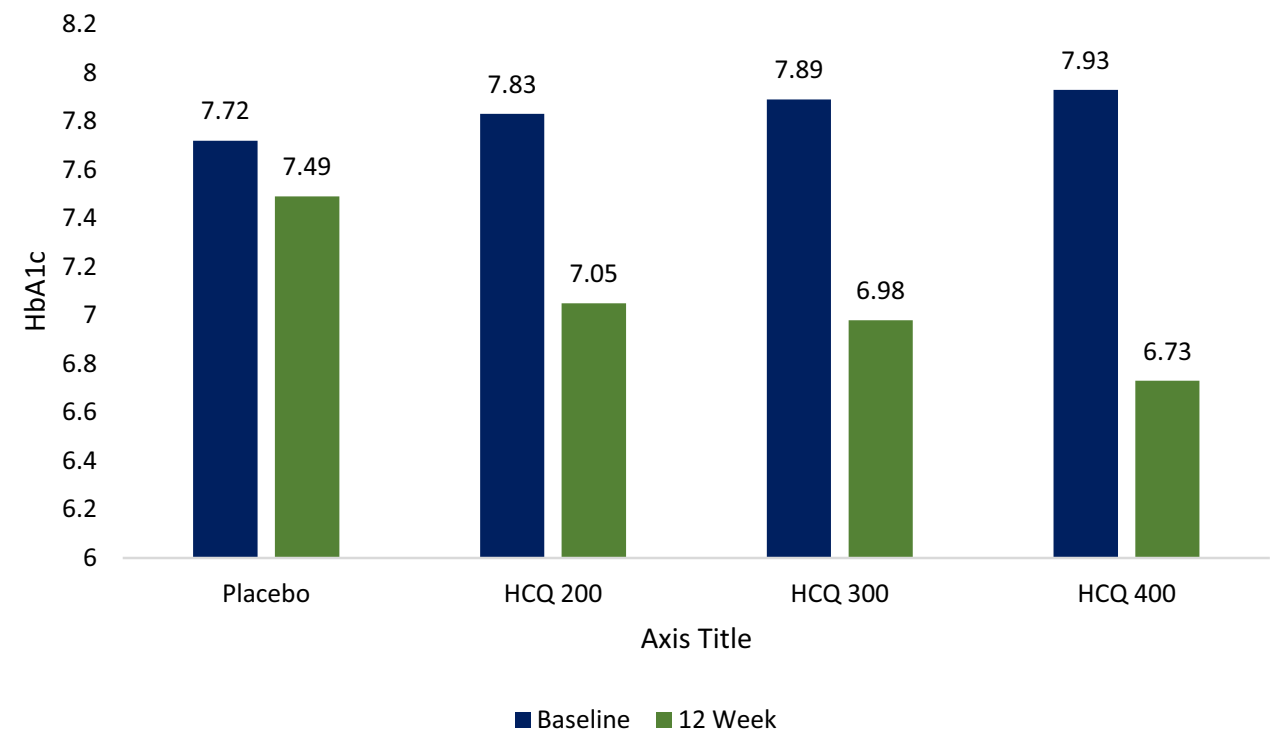

\begin{tabular}{|c|c|c|c|c|c|c|c|}
\hline \multirow[t]{2}{*}{ Characteristics } & \multicolumn{3}{|c|}{$\begin{array}{l}\text { Met + SU + HCQ } 200 \mathrm{mg} \mathrm{BD} \\
(N=70)\end{array}$} & \multicolumn{3}{|c|}{$\begin{array}{l}\text { Met + SU + HCQ } 400 \mathrm{mg} \text { OD } \\
(N=51)\end{array}$} & \multirow[t]{2}{*}{$P$ value } \\
\hline & Baseline & 12 week & $P$ value & Baseline & 12 week & $P$ value & \\
\hline Weight $(\mathrm{kg})$ & $70.7 \pm 8.2$ & $69.4 \pm 7.5$ & 0.010 & $70.7 \pm 8.2$ & $68.8 \pm 7.1$ & 0.12 & 0.219 \\
\hline $\operatorname{HbA1C}(\%)$ & $7.93 \pm 0.5$ & $7.31 \pm 0.5$ & $<0.005$ & $7.93 \pm 0.5$ & $7.39 \pm 0.5$ & $<0.005$ & 0.749 \\
\hline FPG (mg/dl) & $170 \pm 45$ & $114 \pm 21$ & $<0.005$ & $170 \pm 45$ & $111 \pm 26$ & $<0.005$ & 0.843 \\
\hline PPG (mg/dl) & $282 \pm 51$ & $189 \pm 36$ & $<0.005$ & $282 \pm 51$ & $182 \pm 34$ & $<0.005$ & 0.894 \\
\hline
\end{tabular}

Fig. 3 Mean change in FPG and PPG from baseline to week 12 in subjects with type 2 diabetes on metformin and sulfonylurea after addition of hydroxychloroquine or placebo

Table 3 Change in weight and glycemic parameters from baseline at further follow-up at Week 12

\section{Baseline FPG/PPG}

$157 / 269 \quad 164 / 275 \quad 168 / 278$

$170 / 282$

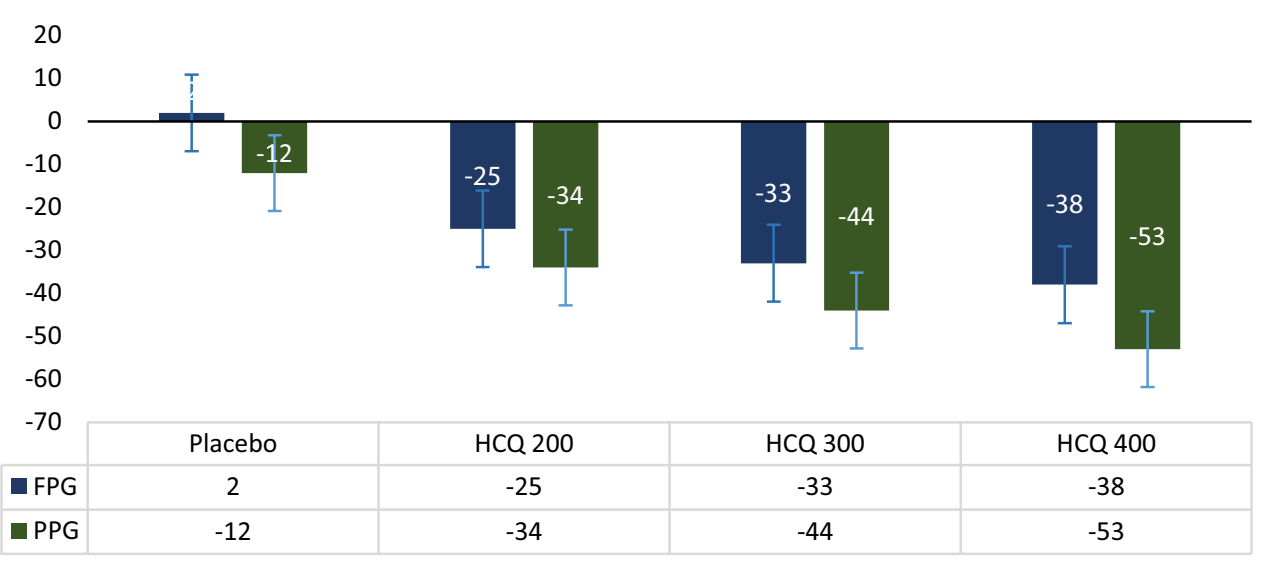

$\square \mathrm{FPG} \square \mathrm{PPG}$

\begin{tabular}{lllll}
\hline Variables & $\begin{array}{l}\text { Met + SU + placebo } \\
(N=61)\end{array}$ & $\begin{array}{l}\text { Met + SU + HCQ } \\
200 \mathrm{mg}(N=61)\end{array}$ & $\begin{array}{l}\text { Met + SU + HCQ } \\
300 \mathrm{mg}(N=61)\end{array}$ & $\begin{array}{l}\text { Met + SU + HCQ } \\
400 \mathrm{mg}(N=121)\end{array}$ \\
\hline HbA1C $<7.0 \%$ & 0 & $4(6.5 \%)$ & $12(19.6 \%)$ & $32(26.4 \%)$ \\
\hline
\end{tabular}


Fig. 4 Change in body weight from baseline to week 12 in subjects with type 2 diabetes on metformin and sulfonylurea after addition of hydroxychloroquine or placebo



Table 5 Summary of AEs after 12 weeks of treatment

\begin{tabular}{|c|c|c|c|c|}
\hline & $\begin{array}{l}\text { Met }+\mathrm{SU}+\text { placebo } \\
(N=61)\end{array}$ & $\begin{array}{l}\text { Met + SU + HCQ } \\
200 \mathrm{mg}(N=61)\end{array}$ & $\begin{array}{l}\text { Met + SU + HCQ } \\
300 \mathrm{mg}(N=61)\end{array}$ & $\begin{array}{l}\text { Met }+ \text { SU + HCQ } \\
400 \mathrm{mg}(N=121)\end{array}$ \\
\hline Subjects with an AE & $21(34.4 \%)$ & $12(19.6 \%)$ & $17(27.8 \%)$ & $38(31.4 \%)$ \\
\hline Subjects with a moderate AE & 0 & 2 & 3 & 5 \\
\hline \multicolumn{5}{|l|}{ Most common AEs } \\
\hline Headache & 2 & 1 & 0 & 1 \\
\hline Fatigue & 1 & 1 & 0 & 0 \\
\hline Weight increased & 12 & 1 & 0 & 0 \\
\hline Symptomatic hypoglycemia events & 0 & 2 & 3 & 5 \\
\hline $\begin{array}{l}\text { Severe hypoglycemia (that requires assis- } \\
\text { tance from another person to treat) }\end{array}$ & 0 & 0 & 0 & 0 \\
\hline Gastrointestinal (GI) disturbances & 1 & 2 & 6 & 16 \\
\hline Flatulence & 0 & 2 & 1 & 4 \\
\hline Constipation & 0 & 0 & 1 & 3 \\
\hline Upper respiratory tract infection & 1 & 1 & 0 & 1 \\
\hline Rise in CPK level & 1 & 0 & 0 & 0 \\
\hline Urinary tract infection & 2 & 0 & 1 & 1 \\
\hline Dyslipidemia & 1 & 0 & 0 & 0 \\
\hline Deaths & 0 & 0 & 0 & 0 \\
\hline Pain in extremity & 1 & 0 & 0 & 0 \\
\hline Pigmentation & 0 & 0 & 0 & 2 \\
\hline Non-proliferative diabetic retinopathy & 1 & 0 & 0 & 0 \\
\hline Chest pain & 1 & 0 & 0 & 0 \\
\hline
\end{tabular}

Data are $n(\%)$ unless otherwise indicated

incidence compared with placebo, across the once-daily treatment groups.

The main purpose of further 12 week study was to determine that what the glycemic control was if $400 \mathrm{mg}$ OD further divided to $200 \mathrm{mg}$ BD with a special interest to observe the effect on AE which was related to higher dose of hydroxychloroquine. It was been observed that with divided dose of hydroxychloroquine $200 \mathrm{mg}$ BD the gastrointestinal side effects was drastically bring down (Table 6). 
Table 6 Summary of AEs at further follow-up at week 12

\begin{tabular}{lll}
\hline & $\begin{array}{l}\text { Met }+ \text { SU + HCQ 200 mg BD } \\
(N=70)\end{array}$ & $\begin{array}{l}\text { Met + SU + HCQ } \\
400 \mathrm{mg} \text { OD } \\
(N=51)\end{array}$ \\
\hline Symptomatic hypoglycemia events & 2 & 3 \\
Gastrointestinal (GI) disturbances & 2 & 8 \\
Flatulence & 0 & 1 \\
Constipation & 0 & 1 \\
Diarrhoea & 0 & 1 \\
Pigmentation & 0 & 1 \\
\hline
\end{tabular}

\section{Discussion}

Diabetes is a huge and growing problem, and the cost to society is very high and escalating. Type 2 diabetes is a major risk factor for developing both microvascular and macrovascular complications (15). The primary goal of treatment is to target glycemic control by maintaining the HbA1c level near 6-7\% to decrease the incidence of microvascular and macrovascular complications without predisposing patients to hypoglycemia (16). Subjects with T2DM often begins treatment by taking oral agents, usually metformin or a sulfonylurea, and then progress to the combination of these two agents.

Hydroxychloroquine was approved by Drug Controller General of India (DCGI) as an adjunct to diet and exercise to improve glycemic control of patients on metformin, sulfonylurea combination in T2DM. By increasing the intracellular $\mathrm{pH}$, Hydroxychloroquine inhibits various insulin degrading enzymes [17] and thus inhibits insulin degradation [18]. The present study demonstrated the beneficial effect on overall glycemic control of additional hydroxychloroquine therapy in subjects insufficiently controlled by metformin and sulfonylurea combination. Even a significant percentage of patients had achieved target $\mathrm{HbA} 1 \mathrm{c}<7.0 \%$ at week 12 of the study.

Rise in inflammatory markers may occur in diabetes and even in prediabetes stage. This can be postulated from the face that both micro vascular and macro vascular complications are noted in prediabetes stage. Hydroxychloroquine lowers pancreatic levels of CRP, TNF alpha, PG, IL-1 and IL-6 [19, 20]. Hydroxychloroquine increases total concentration of circulating adiponectin levels by $18.7 \%$ [21]. It reduces adipocyte inflammation and islet inflammation which in turn reduces insulin resistance and insulin insufficiency and thus works in T2DM. In a study conducted by Rekedal et al. [22] in RA with diabetes, $0.66 \%$ reduction in baseline $\mathrm{HbA} 1 \mathrm{c}$ post 12 months with hydroxychloroquine use was observed. Hydroxychloroquine shown favourable effects on both glucose control and lipid profiles beyond its anti-inflammatory role. Use of Hydroxychloroquine in T2DM is independently associated with a significant decrease in LDL, total cholesterol, LDL/HDL and total cholesterol/HDL [12]. It also improves insulin sensitivity in non-diabetic obese individual [23].

In multiple recently conducted observational studies, hydroxychloroquine at $400 \mathrm{mg}$ dose exhibit a potent glycemic control, when compared to newer DCGI approved antidiabetic agents like teneligliptin [24, 25].

Efficacy of hydroxychloroquine was dose dependent. Higher the dose of hydroxychloroquine provides higher reduction of glycemic parameters. Even in another Indian trial hydroxychloroquine $400 \mathrm{mg}$ reduced $\mathrm{HbA} 1 \mathrm{c}$ at tune of $1.3 \%$ whereas hydroxychloroquine $200 \mathrm{mg}$ reduced the same by $0.8 \%$ over 24 week [26]. In this RCT trial also it has been seen that the glycemic effect of hydroxychloroquine was dose dependent. There was a significant HbA1c reduction with all the dose of hydroxychloroquine. With regard to the anti-inflammatory effect of hydroxychloroquine in T2DM, Amit Gupta [27] has recently shown that diabetic patients with higher baseline levels of high sensitivity C-reactive protein (hs-CRP $>3 \mathrm{mg} / \mathrm{l}$ ) exhibited a more pronounced, although not significant, improvement in glucose control from baseline to 48 weeks after the initiation of hydroxychloroquine therapy, as compared to patients with lower baseline levels of hs-CRP $(\leq 3 \mathrm{mg} / \mathrm{l})$.

The current RCT trial is the first trial to show that even type 2 diabetes patients who were below $60 \mathrm{~kg}$ of body weight can get the benefit from lower dose of hydroxychloroquine i.e., hydroxychloroquine $200 \mathrm{mg}$ and hydroxychloroquine $300 \mathrm{mg}$. We have shown that weight based dosing can be an ideal option for choosing hydroxychloroquine as an add-on antidiabetic treatment.

The half-life of Hydroxychloroquine is 50 days. In the setting of RA and lupus the drug is slow acting but in a diabetic patients Quatraro et al. [28] showed that Hydroxychloroquine decreased the glucose profile within 10-14 days. In the Indian study use of hydroxychloroquine as an add-on to metformin and sulfonylurea resulted in $\mathrm{HbA} 1 \mathrm{c}$ reduction of $0.56 \%$ at week 12 and $0.87 \%$ at 24 weeks. In this trial a statistically significant reduction was observed even at week 12 among all across hydroxychloroquine group [12]. 
In the present study, across the hydroxychloroquine group body weight was decreased significantly. The reason that weight was found to be decreased by hydroxychloroquine treatment in the present study is not clear. A study published in 2015 in the journal Heart Rhythm found that the mice who consumed the Hydroxychloroquine do not show any weight gain or weight loss [29].

Although there was no incidence of 'major hypoglycemia', all episodes of hypoglycemia resolved or subsided after the patient's ingested glucose or food at their own discretion. The incidence rates of hypoglycemia were low throughout the study and did not increase during any specific period. The probable reason for less incidence of hypoglycaemia with Hydroxychloroquine may because of its actions at peripheral levels i.e. insulin degradation in the target cells and thus facilitate insulin recycling, unlike any secretagogue. Mirza S et al. [30] mentioned odd ratios of IL-6 and other cytokines is a sensitive physiological markers of subclinical inflammation, associated with hyperglycemia, insulin resistance and overt T2DM. Effect of hydroxychloroquine on IL-6 and cytokine may responsible for less hypoglycemia as seen in several trails including the current one. In the Indian RCT study the incidence of hypoglycemia was $0 \%$ in the hydroxychloroquine group while it was $1.5 \%$ in the pioglitazone group when used as add-on to metformin and sulfonylurea [12].

While GI side-effects were more frequent among hydroxychloroquine treated patients. This AE was at comparatively high with maximum dose of hydroxychloroquine i.e. with $400 \mathrm{mg}$. For this reason further it was studied that if hydroxychloroquine was given at divided dose of $200 \mathrm{mg}$ $\mathrm{BD}$ instead of $400 \mathrm{mg}$ OD what could be the difference in efficacy and GI tolerance. It has been seen that when hydroxychloroquine $400 \mathrm{mg}$ was substitute with $200 \mathrm{mg}$ BD there was almost same efficacy in reducing further glycemic parameters and number of patients who earlier complain of GI disturbance and other GI related side effect were significantly decreased.

The anti-inflammatory drugs can be important in the prevention of major cardiovascular event like MI, stroke, and cardiovascular death. Some evidence is available for the beneficial impact of hydroxychloroquine on cardiovascular risk, particularly in diabetes and dyslipidemia. The antiinflammatory agents frequently prescribed in RA or psoriatic arthritis are being evaluated in the management of CVD. Similarly, the role of hydroxychloroquine has been already established to control CVD like MI in high risk individuals such as RA patients.

Cardiac safety studies, particularly the electrophysiological implications for HCQ, have predominantly been evaluated on the basis of its use as an antimalarial treatment and prophylactic. When looking to repurpose hydroxychloroquine for managing diabetes patients, it is essential that the presence or absence of QT interval prolongation in patients are taken into consideration [31]. A retrospective study (from January 1, 2001-October 31, 2013, excluding patients with CVD prior to RA diagnosis) done by Sharma TS et al., confirms that hydroxychloroquine use was associated with a $72 \%$ decrease in the risk of incident CVD in RA patients [32]. The authors also commented that the biological plausibility of this protective association is supported by the favourable associations of hydroxychloroquine with glucose and lipids in RA patients and with thrombosis in lupus patients and nonrheumatic patients [32]. A retrospective study recently published has also confirmed the cardiac safety of hydroxychloroquine [33]. In this study researcher evaluated effect of hydroxychloroquine/Chloroquine (HCQ/ CQ) on TdP/QT using data from the U.S. Food and Drug Administration's Adverse Event Reporting System (FAERS) ( $>13$ million total report analysed incorporating extensive safety data of last 50 rears, 1969-2019). Lower 95\% Cls for HCQ/CQ alone showed no potential safety signals for $\mathrm{TdP} / \mathrm{QT}$ prolongation, death or accident/injuries or depression [PRRs and 95\% Cls for TdP/QT prolongation was 1.43 (1.29-2.59)] [33]. As a cardio vascular safety hydroxychloroquine also has been associated with beneficial changes in lipid profiles, including decrease in low- density lipoprotein and total cholesterol, which result in a less atherogenic lipid profile [34-36]. Even prior to the advances in current antithrombotic therapies, hydroxychloroquine was used perioperatively for deep venous thrombosis prophylaxis in abdominal and orthopaedic surgeries [37-39]. Studies had already confirmed that hydroxychloroquine use was associated with reduced risk of thrombotic events in patients with lupus and antiphospholipid syndrome [40]. Even it had been found that hydroxychloroquine acts as a bradycardic agent in SAN cells, in atrial preparations and in vivo and lows the rate of spontaneous action potential firing in the SAN through multichannel inhibition, including that of $I_{f}$ [41]. This documentations probably explains the protective CVD association seen with hydroxychloroquine which can be even true in patients with diabetes.

Ocular toxicity is the most important concern linked with chronic use of hydroxychloroquine. To manage ocular risk, use of minimum effective dose of hydroxychloroquine and periodic ophthalmological screening is recommended. We have already used recommended dose of hydroxychloroquine in this current trial as per recommendation from AAO to avoid ocular toxicity. A recent findings from large cohort study $(N=2867)$ from Cleveland with follow-up from 1999 to 2017 has confirm that only 31 patients had visual impairment and majority were due to comorbidities such as diabetes, hypertension, stroke, cardiac arrest etc. [42] This study also confirmed that even after long-term use in diabetic patients HCQ is safe [42]. It recommended that, the baseline ophthalmological screening should be done before 
initiation of hydroxychloroquine therapy and yearly screening should be performed after five years of use when risk factors are absent. Regular yearly ophthalmological screening is recommended for the patients with risk factors.

Like many other countries in the world India has also been affected by COVID-19 pandemic and at the time of writing this article, there are already more than 100,000 cases of COVID-19 infection, and more than 3000 individuals have died of the disease in India. Emerging evidence suggest that for COVID-19, most prevalent comorbidities id diabetes and also for a worse prognosis of the disease it is one of the major risk factors [43-51]. Antihypoglycemic property of hydroxychloroquine in patients with diabetes and the risk benefits at the time of COVID-19 pandemic is major subject of discussion. Emerging evidence with regards to the current pandemic scenario shows that following COVID-19 infection diabetic patients have a greater risk for adverse outcomes [52]. There are several review articles published which support the effect of hydroxychloroquine in the early infection stage of COVID-19 [53-55]. Further more recent study confirms that countries who were using antimalarial drugs has much lesser death rates as compare to countries which do not [56]. Although findings from clinical studies have also suggested limited benefit from hydroxychloroquine in COVID-19 in general [57], several randomized controlled trials are currently investigating the use of HCQ for prophylaxis of COVID-19 [58]. Moreover, guidelines from different countries have listed some investigational drugs (including hydroxychloroquine) as potential adjuvant treatment options $[57,59]$.

Thus the authors of this trial hope that the findings from this RCT will help great number of uncontrolled diabetes patients in developing country like India to achieve their glycemic target.

Sample size of the trial was small, further large scale data with longer duration of time thorough ophthalmologic monitoring and cardiovascular outcomes assessments required to established further effectiveness of different doses of HCQ as add-on treatment for T2DM.

\section{Conclusion}

Hydroxychloroquine added to sulphonylurea and metformin, improves glycemic control significantly in T2DM patients. Glycemic effect of different dose of hydroxychloroquine is dose dependent. The safety/tolerability profile of hydroxychloroquine was favourable except GI disturbance which more frequent with $400 \mathrm{mg}$. This can be avoided with $200 \mathrm{mg}$ BD without compromise on efficacy. Even type 2 diabetes patients who were below $60 \mathrm{~kg}$ of body weight can get the benefit from lower dose of hydroxychloroquine i.e., hydroxychloroquine $200 \mathrm{mg}$ and hydroxychloroquine
$300 \mathrm{mg}$. We have shown that weight based dosing can be an ideal option for choosing hydroxychloroquine as an add-on antidiabetic treatment.

Acknowledgments This research did not receive specific funding, but was performed as part of the employment of the authors, at Kolkata Medical College and Hospital. We gratefully appreciate all departmental staff of Calcutta Medical College and Hospital for supporting us throughout the research and the study participants for their meticulous information.

Author contributions AN: retrieved patient's data, drafted and reviewed the paper. HNC: retrieved patient's data, drafted and reviewed the paper. All authors meet the International Committee of Medical Journal Editors (ICMJE) criteria for authorship for this manuscript, take responsibility for the integrity of the work as a whole, and have given final approval for the version to be published.

\section{Compliance with ethical standards}

Conflicts of interest The authors declare that there are no conflicts of interest regarding the publication of this paper.

Ethical approval Ethical clearance to conduct this study was obtained from the Institutional Ethics Committee, Medical College, Kolkata (Ref No. MC/kol/IEC/Non-spon/641/11-2017). Ethical Review Committee Board.

Research involving human participants and/or animals All procedures performed in studies involving human participants were in accordance with the ethical standards of the institutional research committee and with the Helsinki declaration.

Informed consent Participants were informed about the study, and those who agreed to participate provided a written or verbal consent. Confidentiality was assured throughout the study.

Open Access This article is licensed under a Creative Commons Attribution 4.0 International License, which permits use, sharing, adaptation, distribution and reproduction in any medium or format, as long as you give appropriate credit to the original author(s) and the source, provide a link to the Creative Commons licence, and indicate if changes were made. The images or other third party material in this article are included in the article's Creative Commons licence, unless indicated otherwise in a credit line to the material. If material is not included in the article's Creative Commons licence and your intended use is not permitted by statutory regulation or exceeds the permitted use, you will need to obtain permission directly from the copyright holder. To view a copy of this licence, visit http://creativecommons.org/licenses/by/4.0/.

\section{References}

1. International Diabetes Federation. IDF Diabetes Atlas-7th Edition. https://www.idf.org/e-library/epidemiology-research/diabe tes-atlas/13-diabetes-atlas-seventh-edition.html

2. International Diabetes Federation (2015) IDF Diabetes Atlas, 7th edn. International Diabetes Federation, Brussels, Belgium

3. Gong L, Goswami S, Giacomini KM, Altman RB, Klein TE (2012) Metformin pathways: pharmacokinetics and 
pharmacodynamics. Pharmacogenet Geno 22(11):820. https:// doi.org/10.1097/FPC.0b013e3283559b22 (PMID: 22722338))

4. American Diabetes Association (2012) Executive summary: standards of medical care in diabetes-2012. Diabetes Care 35(Suppl 1):S4-S10. https://doi.org/10.2337/dc12-s004

5. Inzucchi SE, Bergenstal RM, Buse JB et al (2012) Management of hyperglycemia in type 2 diabetes: a patient-centered approach: position statement of the American Diabetes Association (ADA) and the European Association for the Study of Diabetes (EASD). Diabetes Care 35:1364-1379. https://doi.org/10.2337/dc12-0413 (PMID: 22517736))

6. Zinman B (2011) Initial combination therapy for type 2 diabetes mellitus: is it ready for prime time? Am J Med 124:S19-34. https ://doi.org/10.1016/j.amjmed.2010.11.003 (PMID: 21194577))

7. (2016) Standards of medical care in diabetes-2016: summary of revisions. Diabetes Care 39(Suppl 1):S4-S5. https://doi. org/10.2337/dc16-S003

8. Kalra S, Das AK, Sahay RK et al (2019) Consensus Recommendations on GLP-1 RA Use in the Management of Type 2 Diabetes Mellitus: South Asian Task Force. Diabetes Ther 10(5):16451717. https://doi.org/10.1007/s13300-019-0669-4 (PMID: 31359367))

9. Lecka-Czernik B (2010) Bone loss in diabetes: use of antidiabetic thiazolidinediones and secondary osteoporosis. Curr Osteoporos Rep 8(4):178-184. https://doi.org/10.1007/s11914-010-0027-y (PMID: 20809203))

10. Bajaj S (2018) RSSDI clinical practice recommendations for the management of type 2 diabetes mellitus 2017. Int J Diabetes Dev Ctries 38(Suppl 1):1-115. https://doi.org/10.1007/s13410-0180604-7 (PMID: 29527102))

11. Gerstein HC, Thorpe KE, Taylor DW, Haynes RB (2002) The effectiveness of hydroxychloroquine in patients with type 2 diabetes mellitus who are refractory to sulfonylureas - a randomized trial. Diabetes Res Clin Pract 55(3):209-219. https://doi. org/10.1016/S0168-8227(01)00325-4 (PMID: 11850097)

12. Pareek A, Chandurkar N, Thomas N, Viswanathan V, Deshpande A, Gupta OP, Shah A, Kakrani A, Bhandari S, Thulasidharan NK, Saboo B (2014) Efficacy and safety of hydroxychloroquine in the treatment of type 2 diabetes mellitus: a double blind, randomized comparison with pioglitazone. Curr Med Res Opin 30(7):12571266. https://doi.org/10.1185/03007995.2014.909393 (PMID: 24669876)

13. Marmor MF, Kellner U, Lai TY et al (2011) Revised recommendations on screening for chloroquine and hydroxychloroquine retinopathy. Ophthalmology 118:415-422. https://doi.org/10.1016/j. ophtha.2010.11.017 (PMID: 21292109)

14. Marmor MF, Kellner U, Lai TYY et al (2016) Recommendations on screening for chloroquine and hydroxychloroquine retinopathy (2016 revision). Ophthalmology 123:1386-1394. https://doi. org/10.1016/j.ophtha.2016.01.058 (PMID: 26992838)

15. Group UPDS (1998) Effect of intensive blood-glucose control with metformin on complications in overweight patients with type 2 diabetes (UKPDS 34). Lancet 352:854-865. https://doi. org/10.1016/S0140-6736(98)07037-8

16. Choy M, Lam S (2007) Sitagliptin: a novel drug for the treatment of type 2 diabetes. Cardiol Rev 15:264-271. https://doi. org/10.1097/CRD.0b013e318123f771

17. Emami J, Gerstein HC, Pasutto FM et al (1999) Insulin-sparing effect of hydroxychloroquine in diabetic rat is concentration dependent. Can J Physiol Pharmacol 77:118-123

18. Emami J, Pasutto F, Mercer JR et al (1999) Inhibition of insulin metabolism by hydroxychloroquine and its enantiomers in cytosolic fraction of liver homogenates from healthy and diabetic rats. Life Sci 64:325-335
19. Pradhan AD, Manson JE, Rifai N et al (2001) C-reactive protein, interleukin-6, and risk of developing type-2 diabetes mellitus. JAMA 286:327-334

20. Silva J, Mariz H, Rocha L et al (2013) Hydroxychloroquine decreases Th17-related cytokines in systemic lupus erythematosus and rheumatoid arthritis patients. Clinics 68:766-771. https ://doi.org/10.6061/clinics/2013(06)07 (PMID: 23778483)

21. Wasko MC, McClure CK, Kelsey SF, Huber K, Orchard T, Toledo FG (2015) Antidiabetogenic effects of hydroxychloroquine on insulin sensitivity and beta cell function: a randomised trial. Diabetologia 58(10):2336-2343. https://doi.org/10.1007/s00125-0153689-2 (PMCID: PMC4575248)

22. Rekedal L, Massarotti E, Garg R et al (2010) Changes in glycated hemoglobin after initiation of hydroxychloroquine or methotrexate in diabetic patients with rheumatic diseases. Arthritis Rheum 62:3569-3573. https://doi.org/10.1002/art.27703 (PMID: 20722019)

23. Mercer E, Rekedal L, Garg R, Lu B, Massarotti EM, Solomon DH (2012) Hydroxychloroquine improves insulin sensitivity in obese non-diabetic individuals. Arthritis Res Ther 14(3):R135. https:// doi.org/10.1186/ar3868 (PMID: 22676348)

24. Jagnani VK, Bhattacharya NR, Satpathy SC, Hasda GC, Chakraborty S (2017) Effect of hydroxychloroquine on type 2 diabetes mellitus unresponsive to more than two oral antidiabetic agents. J Diabetes Metab 8:771. https://doi.org/10.4172/21556156.1000771

25. Singh UP, Baidya A, Singla M, Jain S, Kumar S, Sarogi RK, Gupta A, Ahmed R, Srivastav A, Chauhan DK, Jain N (2018) Efficacy and safety of substituting teneligliptin with hydroxychloroquine in inadequately controlled type 2 diabetes subjects with combination therapy of teneligliptin, metformin and glimepiride with or without other antidiabetic therapy: The TENE-HYQ SHIFT Study. Clini Diabetol 7:209-214. https://doi.org/10.5603/ DK.2018.0025

26. Baidya A, Chakravarti HN, Saraogi RK, Gupta A, Ahmed R et al (2018) Efficacy of maximum and optimum doses of hydroxychloroquine added to patients with poorly controlled type 2 diabetes on stable insulin therapy along with glimepiride and metformin: association of high-sensitive c-reactive protein (hs-crp) and glycosylated haemoglobin (HbA1c). Endocrinol Metab Syndr 7:283. https://doi.org/10.4172/2161-1017.1000283

27. Gupta A (2019) Real-world clinical effectiveness and tolerability of /hydroxychloroquine $400 \mathrm{mg}$ in uncontrolled type 2 diabetes subjects who are not willing to initiate insulin therapy (HYQReal-World Study). Curr Diabetes Rev 15(6):510-519

28. Quatraro A, Consoli G, Magno M et al (1990) Hydroxychloroquine in decompensated, treatment-refractory noninsulin-dependent diabetes mellitus: a new job for an old drug? Ann Intern Med 112:678-688 (PMID:2110430)

29. Capel RA, Herring N, Kalla M et al (2015) Hydroxychloroquine reduces heart rate by modulating the hyperpolarization-activated current If: Novel electrophysiological insights and therapeutic potential. Heart Rhythm 12(10):2186-2194. https://doi. org/10.1016/j.hrthm.2015.05.027 (PMID: 26025323)

30. Mirza S, Hossain M, Mathews C et al (2011) Type 2-diabetes is associated with elevated levels of TNF-alpha, IL-6 and adiponectin and low levels of leptin in a population of Mexican Americans: a cross-sectional study. Cytokine 57(1):136-142. https:// doi.org/10.1016/j.cyto.2011.09.029 (PMID: 22035595)

31. Kamalan J (2019) Chloroquine and hydroxychloroquine for COVID-19: implications for cardiac safety. Euro Heart J Phar$\operatorname{maco} 41: 2$

32. Sharma TS, Wasko MC, Tang X, Vedamurthy D, Yan X, Cote J, Bili A (2016) Hydroxychloroquine use is associated with decreased incident cardiovascular events in rheumatoid arthritis 
patients. J Am Heart Assoc 5:e002867. https://doi.org/10.1161/ JAHA. 115.002867

33. Sarayani A, Cicali B, Henriksen CH, Brown JD (2020) Safety signals for QT prolongation or Torsades de Pointes associated with azithromycin with or without chloroquine or hydroxychloroquine. Res Soc Adm Pharm 51(20):30391. https://doi.org/10.1016/j. sapharm.2020.04.016 (PMID: 32327397)

34. Morris SJ, Wasko MC, Antohe JL, Sartorius JA, Kirchner HL, Dancea S, Bili A (2011) Hydroxychloroquine use associated with improvement in lipid profiles in rheumatoid arthritis patients. Arthritis Care Res (Hoboken) 63:530-534

35. Kerr G, Aujero M, Richards J, Sayles H, Davis L, Cannon G, Caplan L, Michaud K, Mikuls T (2014) Associations of hydroxychloroquine use with lipid profiles in rheumatoid arthritis: pharmacologic implications. Arthritis Care Res (Hoboken) 66:1619-1626

36. Pareek A, Chandurkar N, Thulaseedharan N et al (2015) Efficacy and safety of fixed dose combination of atorvastatin and hydroxychloroquine: a randomized, double-blind comparison with atorvastatin alone among Indian patients with dyslipidemia. Curr Med Res Opin 31:2105-2117

37. Wu TK, Tsapogas MJ, Jordan FR (1977) Prophylaxis of deep venous thrombosis by hydroxychloroquine sulfate and heparin. Surg Gynecol Obstet 145:714-718

38. Carter AE, Eban R (1974) Prevention of postoperative deep venous thrombosis in legs by orally administered hydroxychloroquine sulphate. Br Med J 3:94-95

39. Hansen EH, Jessing P, Lindewald H, Ostergaard P, Olesen T, Malver EI (1976) Hydroxychloroquine sulphate in prevention of deep venous thrombosis following fracture of the hip, pelvis, or thoracolumbar spine. J Bone Joint Surg Am 58:1089-1093

40. Petri M (2011) Use of hydroxychloroquine to prevent thrombosis in systemic lupus erythematosus and in antiphospholipid antibody-positive patients. Curr Rheumatol Rep 13:77-80

41. Capel RA et al (2015) Hydroxychloroquine reduces heart rate by modulating the hyperpolarization-activated current $\mathrm{I}_{\mathrm{f}}$ : Novel electrophysiological insights and therapeutic potential. Heart Rhythm 12:2186-2194. https://doi.org/10.1016/j.hrthm.2015.05.027

42. Bhatraju PK, Ghassemieh BJ, Nichols M, Kim R, Jerome KR, Nalla AK et al (2020) Covid-19 in critically Ill patients in the Seattle region - case series. N Engl J Med 34:13-57

43. Singh DK, Muhieddine L, Einstadter D, Ballou S (2019) Incidence of blindness in a population of rheumatic patients treated with hydroxychloroquine. Rheumatol Adv Pract 3(1):009

44. Guan WJ, Liang WH, Zhao Y, Liang HR, Chen ZS, Li YN et al (2020) Comorbidity and it is impact on 1590 patients with Covid19 in China: a Nationwide Analysis. Eur Respir J 5(2):80

45. Zhou F, Yu T, Du R, Fan G, Liu Z et al (2020) Clinical course and risk factors for mortality of adult inpatients with COVID19 in Wuhan, China: a retrospective cohort study. Lancet 395:1054-1062
46. Guo W, Li M, Dong Y, Zhou H, Zang Z, Tian C et al (2020) Diabetes is a risk factor for the progression and prognosis of COVID19. Diabetes Metab Res Rev 33:19

47. Fadini GP, Morieri ML, Longato E, Avogaro A (2020) Prevalence and impact of diabetes among people infected with SARS-C0v-2. J Endocrinol Invest 08:45-120

48. Huang I, Lim MA, Pranata R (2020) Diabetes mellitus is associated with increased mortality and severity of disease in COVID19 pneumonia - a systematic review, meta-analysis, and metaregression. Diabetes Metab Syndr 14(4):395-403

49. Bornstein SR, Dalan R, Hopkins D, Mingrone G, Boehm BO (2020) Endocrine and metabolic link to coronavirus infection. Nat Rev Endocrinol 1:2

50. Muniyappa R, Gubbi S (2020) COVID-19 pandemic, Corona Viruses, and diabetes mellitus. Am J Physiol Endocrinol Metab 13:15-38

51. Drucker DJ (2020) Coronavirus infections and type 2 diabetesshared pathways with therapeutic implications. Endocr Rev 1:23

52. Infante M, Ricordi C, Fabbri A (2020) Antihyperglycemic properties of hydroxychloroquine in patients with diabetes: risk and benefits at the time of COVID-19 pandemic. J Diabetes. https:// doi.org/10.1111/1753-0407.13053

53. Ceriello A, Stoian AP, Rizzo M (2020) COVID-19 and diabetes management: what should be considered? Diabetes Res Clin Pract 163:108-151

54. Bhadada SK (2020) Should anti-diabetic medications be reconsidered amid COVID-19 pandemic? Diabetes Res Clin Pract. https:// doi.org/10.1016/j.diabres.2020.108146

55. Singh AK, Singh A, Shaikh A, Singh R, Mishra A (2020) Chloroquine or hydroxychloroquine in the treatment of COVID-19 with or without diabetes: a systematic search and a narrative review with special reference to India and other developing countries. Diabetes Metab Syndr 14(3):241-246

56. Xu X, Ong YK, Wang Y (2020) Role of adjunctive treatment strategies in COVID-19 and a review of International and national clinical guidelines. Mil Med Res 7(1):22

57. https://clinicaltrials.gov ("condition or disease": COVID "other terms" hydroxychloroquine). Accessed 19 Apr 2020.

58. Izoulet $M(2019)$ National consumption of antimalarial drugs and covid-19 deaths dynamics: can ecological study. Ecologicalogy $1: 4$

59. Lombardy Section Italian Society Infectious And Tropical Diseases (2020) Vademecum for the treatment of people with COVID-19. Edition 2.0, 13 March 2020. Infez Med 28(2):143-152

Publisher's Note Springer Nature remains neutral with regard to jurisdictional claims in published maps and institutional affiliations. 